\title{
ESTUDO DAS TÉCNICAS EXPERIMENTAIS DE DIFRAÇÃO DE RAIOS X PARA CARACTERIZAÇÃO DE AMOSTRAS METÁLICAS*
}

\author{
Beatriz Sampaio Torres ${ }^{1}$ \\ Ariel José Assayag do Lago ${ }^{1}$ \\ Géssica Seara Faria ${ }^{2}$ \\ Juciane Maria Alves ${ }^{3}$ \\ Talita Gama de Sousa ${ }^{3}$ \\ Wagner Anacleto Pinheiro 4 \\ Paulo Roberto Rodrigues de Jesus ${ }^{5}$ \\ Luiz Paulo Mendonça Brandão ${ }^{6}$
}

\section{Resumo}

A técnica de difração de raios $X$ permite a obtenção de diversos resultados referentes à caracterização de determinado material. Através dela, foi possível realizar cinco experimentos em amostras metálicas submetidas a diferentes preparos, dentre eles: análise qualitativa, cálculo do parâmetro de rede, análise de orientação preferencial, análise de tamanho de cristalito e análise quantitativa. Os resultados obtidos foram condizentes com o previsto pela teoria, ratificando a eficiência da técnica.

Palavras-chave: DRX; Refinamento Rietveld; Textura.

\section{STUDY OF EXPERIMENTAL X-RAY DIFFERENT TECHNIQUES FOR CHARACTERIZATION AND METALLIC SAMPLES}

\section{Abstract}

The X-ray diffraction technique allows to obtain several results regarding the characterization of a given material. Through it, it was possible to perform five experiments on metallic samples submitted to different preparations, among them: qualitative analysis, lattice parameter calculation, preferred orientation analysis, crystallite size analysis and quantitative analysis. The results obtained were consistent with the theory, confirming the efficiency of the technique.

Keywords: DRX, Rietveld Refinament, Preferred Orientation.

1 Aluno graduação Engenharia de Materiais, Seção de Engenharia Mecânica e de Materiais, Instituto Militar de Engenharia, Rio de Janeiro, RJ, Brasil.

2 Engenheira Metalúrgica, mestranda em Ciências dos Materiais, Seção de Engenharia Mecânica e de Materiais, Instituto Militar de Engenharia, Rio de Janeiro, RJ, Brasil.

3 Tecnologista em Processos Químicos, doutoranda em Ciências dos Materiais, Seção de Engenharia Mecânica e de Materiais, Instituto Militar de Engenharia, Rio de Janeiro, RJ, Brasil.

4 Engenheiro Metalúrgico, doutor em Ciências dos Materiais, professor/coordenador, Seção de Engenharia Mecânica e de Materiais, Instituto Militar de Engenharia, Rio de Janeiro, RJ, Brasil.

5 Engenheiro de Materiais, mestre em Ciências dos Materiais, professor, Seção de Engenharia Mecânica e de Materiais, Instituto Militar de Engenharia, Rio de Janeiro, RJ, Brasil.

6 Engenheiro Metalúrgico, doutor em Engenharia Metalúrgica e de Materiais, professor, Seção de Engenharia Mecânica e de Materiais, Instituto Militar de Engenharia, Rio de Janeiro, RJ, Brasil.. 


\section{INTRODUÇÃO}

A técnica de difração de raios $X$ permite a análise tanto qualitativa quanto quantitativa de diversas propriedades dos materiais, o que confere grande utilização no meio científico. Consiste na irradiação da amostra com um feixe de raios $X$ provenientes de tubos geradores desses tipos de onda.

O resultado do experimento, um difratograma, relaciona a intensidade da onda difratada com o ângulo $2 \theta$ do difratômetro onde esta foi medida. Os dados deste gráfico podem ser analisados de diversas maneiras para se extrair as informações desejadas.

\subsection{Análise Qualitativa}

Cada material possui um padrão de difração diferente, de acordo com os picos apresentados e seus respectivos ângulos $2 \theta$, indicadores de sua estrutura cristalina e parâmetro de rede [1]. Baseado nisso, a técnica de difração de raios $X$ pode ser utilizada para que se descubra o material constituinte de determinada amostra.

\subsection{Cálculo do parâmetro de rede}

A partir da identificação do material, pode-se verificar o sistema cristalino do qual faz parte e calcular seu parâmetro de rede. Esse cálculo é fundamental para compreender a estrutura cristalina do material e, com isso, poder explicar fenômenos como transformações de fase, afinidade para formação de ligas, defeitos etc.

Partindo de um sistema cúbico, o parâmetro de rede pode ser alcançado a partir de dois tipos de métodos. O primeiro deles são os métodos de aproximação, os quais compreendem o Método Teórico e o Método Analítico. O segundo são os métodos de precisão, como o Método da Extrapolação (Nelson Riley) e o Método do Difratômetro (Cohen). De acordo com a referência [2], sabe-se como utilizar cada um desses métodos e como apresentar os resultados de uma forma adequada.

Os métodos de aproximação partem da Lei de Bragg. Enquanto o Método Analítico resulta em apenas um valor aproximado, o Teórico resulta em um valor de parâmetro de rede para cada ângulo de difração, e destes parâmetros é recomendado que escolha-se o proveniente de maior $2 \theta$.

Os métodos de precisão partem dos valores obtidos através do Método Teórico e utilizam ferramentas matemáticas distintas para alcançar com relativa precisão um valor de parâmetro de rede. No Método da Extrapolação, utiliza-se a fórmula do erro de Nelson Riley, onde toma-se o valor de menor erro para o parâmetro. Já no Método do Difratômetro, a partir do Método dos mínimos quadrados, é possível encontrar o parâmetro considerando erros sistemáticos.

\subsection{Orientação preferencial}

Para análises de difração ideais, os planos em uma amostra estão distribuídos aleatoriamente. Esta condição pode ser atingida na prática de maneira satisfatória analisando amostras em pó [2].

Em ligas metálicas policristalinas, os planos estão distribuídos ao longo do corpo volumétrico. Empilhamentos de planos com a mesma orientação são denominados grãos cristalográficos. Quando determinadas orientações de grãos são mais frequentes que outras, ocorre o que é chamado de orientação preferencial, ou textura. 
Em processos onde altas taxas de deformação plástica estão envolvidas, grãos cristalográficos tendem a rotacionar no sentido da força aplicada, fazendo com que os grãos se rearranjem em uma orientação preferencial, dando origem a textura [3], [4]. No caso da laminação, os grãos cristalográficos tentem a rotacionar na direção de laminação. Portanto, os planos tendem a se alinhar e, ao fim do processo, origina-se uma orientação preferencial com planos cristalográfico paralelos à face da chapa formada.

A intensidade dos feixes difratados em amostras orientadas preferencialmente difere da intensidade registrada para amostras aleatórias [2]. Planos com maior ocorrência tendem a ter uma intensidade integrada maior do que a registrada no banco de dados (amostras aleatórias). Por meio do desvio da intensidade integrada para os picos registrados no difratograma em relação aos dados de referência das fichas PDF, pode-se determinar se há ocorrência de textura. Este método consiste em uma análise matemática das intensidades integradas. Para cada pico de difração, define-se o coeficiente $C$ :

$$
C_{i}=\frac{\frac{I_{i}}{I_{r e f-i}}}{\frac{\sum \frac{I_{i}}{I_{r e f-i}}}{N}}
$$

Onde $\mathrm{N}$ é o número de picos, $I_{i}$ é a intensidade integrada para o i-ésimo pico do difratômetro e $I_{r e f-i}$ é a intensidade integrada relativa para o i-ésimo pico da ficha PDF de referência. Quando temos para todos os picos $C_{i} \cong 1$, a amostra é considerada orientada aleatoriamente. Caso contrário, há textura presente.

O parâmetro $\sigma=\sqrt{\frac{\sum\left(1-C_{i}\right)^{2}}{N}}$ define quantitativamente o grau de orientação preferencial da amostra. Para amostras aleatórias, $\sigma \cong 1$.

\subsection{Tamanho de cristalito}

Idealmente, os picos de difração são representados em um difratograma por linhas discretas em valores bem definidos de $2 \theta$. Porém, nos experimentos de difração reais, diversos efeitos contribuem para alargar os picos. A medida deste fenômeno é a largura a meia altura, comumente nomeada B.

Os efeitos dos alargamentos que contribuem para produzir a largura à meia altura medida em um difratograma real são representados pela equação de Wiliamson Hall. A referência [2] explica como obter o tamanho de cristalito médio e a deformação residual média a partir dessa equação. Entre esses efeitos, encontramse os de desvio de idealidade do equipamento, principalmente devido ao policromatismo da radiação incidente, 0 do tamanho de cristalito e o das deformações residuais.

\subsection{Análise quantitativa}

Nos processos de caracterização de materiais, faz-se necessário averiguar não só os compostos presentes, mas também o percentual de cada fase constituinte.

Ao longo dos anos, diversas técnicas baseadas na difração de raios $X$ foram desenvolvidas. Uma das técnicas que ganhou destaque na análise qualitativa foi 0 refinamento de dados desenvolvido por Hugo Rietveld. Esta análise matemática baseia-se no método dos mínimos quadrados. Através dele, é gerado um modelo de difratograma, considerando-se diversos parâmetros, dentre eles: parâmetros cristalográficos, microestruturais e do próprio equipamento de difração. 
O método de Rietveld é de grande valia para situações onde há diversas fases presentes no material a ser analisado ou quando a concentração de fases é muito pequena ao ponto de não ser detectável por outros métodos experimentais.

Para assegurar um resultado confiável de refinamento, é necessário que o experimento de difração seja conduzido da maneira mais precisa possível, de preferência com análise de pó para reduzir efeitos de orientação. Também é preciso que seja utilizado um banco de dados atualizado e que os parâmetros do equipamento de difração estejam finamente ajustados no software de cálculo.

Considera-se que o ajuste de Rietveld é estatisticamente satisfatório quando o parâmetro GOF (goodness of fit), que informa o quanto o modelo se aproxima do difratograma experimental, está no intervalo de 1 a 5.

A modelagem matemática deste processo pode ser conduzida de três modos distintos: automático, semi-automático e manual. No primeiro, o software define por si só os parâmetros relevantes para a amostra e conduz com rapidez o refinamento, exibindo em poucos segundos resultados estatisticamente significantes. Os modos semi-automático e manual são semelhantes e, diferentemente do modo automático, permitem a seleção dos parâmetros à critério do operador a fim de refinar os resultados o melhor possível.

\section{MATERIAIS E MÉTODOS}

\subsection{Análise qualitativa}

Utilizou-se uma amostra metálica de cobre na forma de placa. A amostra foi recebida lixada até a granulometria de 2500 e polida quimicamente. Para se obter seu padrão de difração, utilizou-se o difratômetro X'Pert MDR da Panalytical, associado a um tubo de raios $X$ em foco linha com anodo de cobalto e filtro $\$$ beta $\$$ de ferro, com tensão e corrente de trabalho de $40 \mathrm{kV}$ e $45 \mathrm{~mA}$. Realizou-se o experimento de difração de raios $X$ com uma varredura em $2 \theta$ de $40^{\circ}$ a $120^{\circ}$.

Após a coleta de dados, o difratograma resultante foi analisado por meio do software X'Pert HighScore Plus, da Panalytical. A partir dos dados obtidos, é possível determinar as fases presentes na amostra metálica, comparando-se os picos do difratograma obtido com 0 banco de dados de arquivos PFD-2 da Panalytical.

\subsection{Cálculo do parâmetro de rede}

A amostra metálica identificada no experimento de análise qualitativa foi utilizada para o experimento de cálculo de parâmetro de rede. A partir dos dados obtidos pelo difratograma, podem-se extrair as informações necessárias para se calcular o parâmetro de rede pelos diferentes métodos estudados.

\subsection{Orientação preferencial}

Foram analisadas cinco amostras metálicas de cobre puro, sendo a primeira amostra tratada termicamente por recozimento a $600^{\circ} \mathrm{C}$, por 1 hora (CR) e as demais amostras deformadas por laminação, com deformações 30\%, 50\%, 70\% e $85 \%$, respectivamente. As amostras foram lixadas com lixas de carbeto de silício em sequência granulométrica de 400, 600, 1200 e 2500 e em seguidas polidas quimicamente durante $30 \mathrm{~s}$, com solução reativa contendo: 1 parte de ácido nítrico PA; $1 \frac{1}{4}$ partes de ácido acético PA e $2 \frac{3}{4}$ partes de ácido fosfórico PA [5].

A técnica de $D R X$ foi realizada no equipamento X'Pert Pro MRD da PANalytical, utilizando um tubo com fonte de Co $K a(\lambda=1,79 \AA)$, com tensão de 40 
$\mathrm{kV}$ e corrente de $45 \mathrm{~mA}$, e técnica de rotação $\theta-2 \theta$ acoplados. A varredura em $2 \theta$ foi

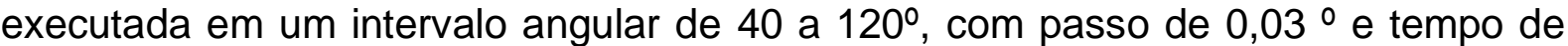
$200 \mathrm{~s}$ por passo. Os ensaios foram realizados na configuração foco linha utilizando $o$ software Data Collector.

Por meio de análise do difratograma resultante no software X'Pert DataViewer, da Panalytical, podem ser extraídos os parâmetros de intensidade para os picos presentes. Além disso, utiliza-se a ficha PDF-2 referente ao material analisado para se proceder com o método de análise da orientação preferencial.

\subsection{Tamanho de cristalito}

Para o estudo de tamanho de cristalino, foram utilizadas duas amostras com deformações por laminação de $50 \%$ e $70 \%$, seguida de recozimento a $500{ }^{\circ} \mathrm{C}$ por uma hora, o qual acarreta na diminuição de tensões internas residuais introduzidas pela deformação e promove recristalização do metal. Receberam mesmo lixamento e polimento que as amostras anteriores, sendo colocadas em posições diametralmente opostas do porta amostra.

Após a coleta de dados, os difratogramas resultantes foram analisados por meio do software X'Pert DataViewer por meio do qual se torna possível a determinação da largura a meia altura dos picos presentes. A partir destes dados, é possível determinar o tamanho de cristalito e a orientação preferencial das amostras de cobre, por meio dos métodos de cálculos introduzidos no presente trabalho.

\subsection{Análise quantitativa}

Utilizou-se uma amostra metálica em pó de constituintes desconhecidos. Para se obter seu padrão de difração, utilizou-se o difratômetro X'Pert MPD da Panalytical, com operação por meio de goniômetro tipo $\theta-2 \theta$,com tubo de raios $X$ de cobre, à tensão e corrente de trabalho de $45 \mathrm{kV}$ e $40 \mathrm{~mA}$. Realizou-se o experimento de difração de raios $X$ com uma varredura em $2 \theta$ de $30^{\circ}$ a $100^{\circ}$.

Inicialmente, devem ser identificadas as amostras pelo mesmo método utilizado para análise qualitativa. Descobertas as fases presentes, devem ser adicionados ao programa fichas com informações cristalográficas que serão utilizadas para a quantificação de fases, as fichas CIF. A partir destes dados, é possível realizar o refinamento de Rietveld com os três modos e quantificar as fases para cada um deles.

\section{RESULTADOS E DISCUSSÃO}

\subsection{Análise qualitativa}

Após a realização da difração de raios $\mathrm{X}$, obteve-se o difratograma exposto na figura 1.

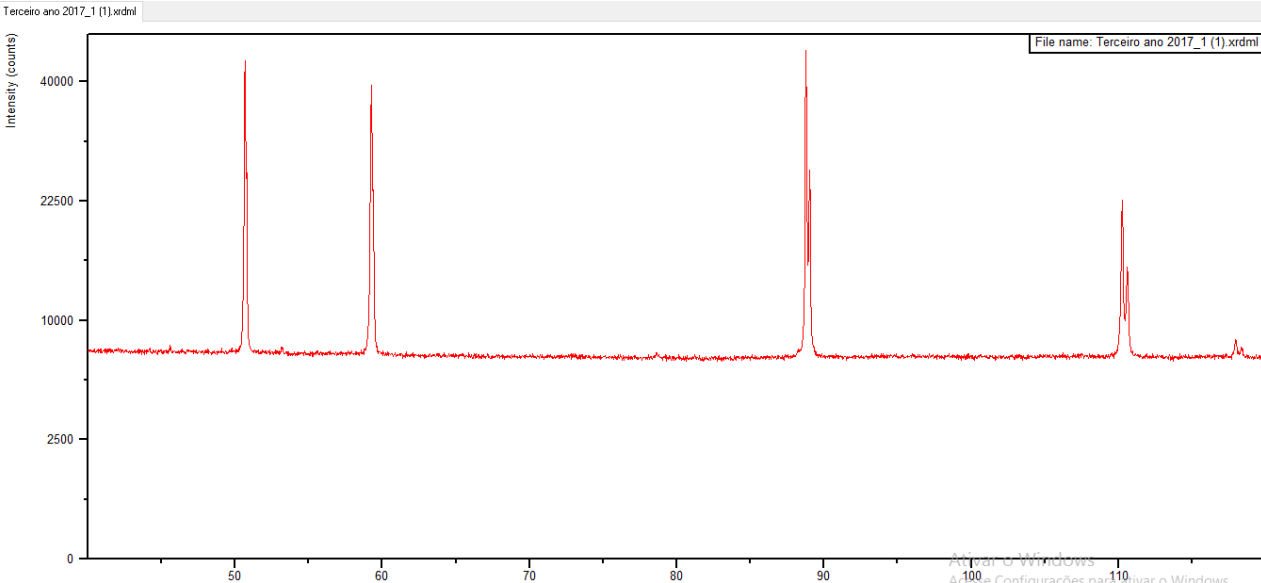


Figura 1. Difratograma resultante do experimento.

Nele puderam ser identificados, por meio de parâmetros do software, os picos $K \alpha_{1}$. Além desses picos, os picos de $K \alpha_{2}$ também foram identificados, porém, foram retirados da análise para que se pudesse ter um registro somente dos picos mais intensos de difração. Com a utilização da base de dados fornecida pelo software foi realizado um processo de verificação da compatibilidade dos picos encontrados com padrões de difração conhecidos de diversas substâncias.

A ficha encontrada com maior compatibilidade e que possuía maior qualidade e confiabilidade dos dados foi a ficha Panalytical 00-004-0836 correspondente ao elemento cobre. A comparação entre os picos registrados na análise e os picos da ficha pode ser observada na figura 2 .

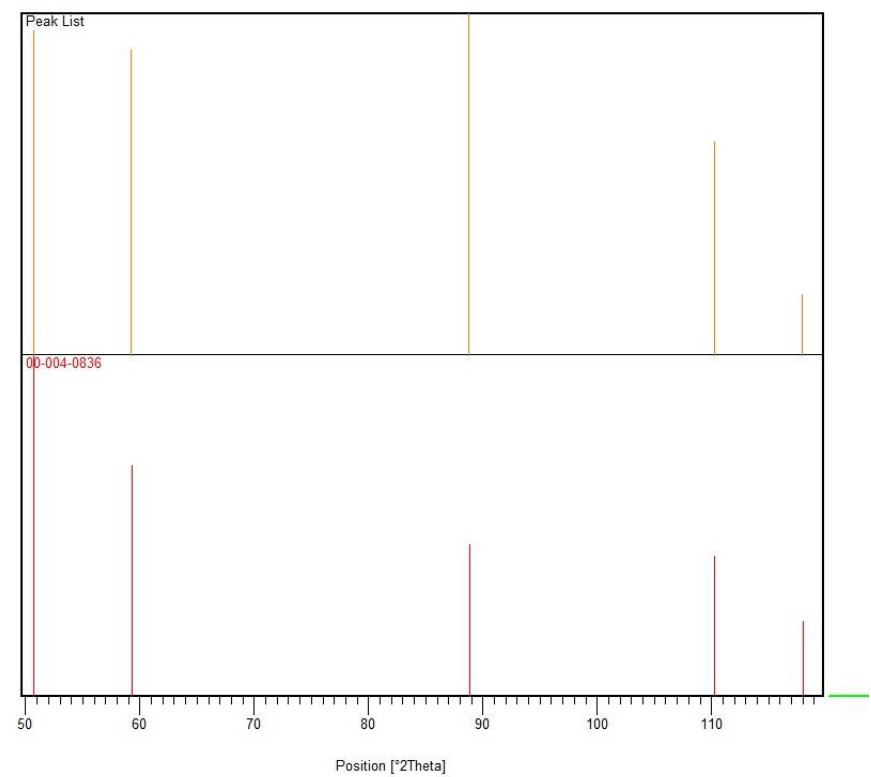

Figura 2. Relação entre os picos da análise e os determinados pelo arquivo PDF 00-004-0836.

Sendo assim, pode-se compreender que a amostra utilizada é constituída por cobre puro, havendo todos os seus picos correspondido ao padrão de difração de tal elemento.

\subsection{Cálculo do parâmetro de rede}

Pelo método teórico para o cálculo do parâmetro de rede identificou-se que o valor de parâmetro de rede mais preciso, ou seja, em um ângulo de difração mais alto, é $a_{\text {teórico }}=3,6159 \AA$ Å.

Além disso, podem ser verificadas as famílias de planos onde ocorre difração. Para este experimento, identificou-se difração nas famílias: $\{111\},\{200\},\{220\},\{311\}$ e \{222\}. Esta configuração coincide com a determinada pelas regras de exclusão do fator de estrutura de uma rede cúbica de face centrada.

Pelo método analítico, pode ser elaborada a tabela 1. Nela, o fator em negrito é o menor coeficiente que se repete nas colunas. Da teoria do método, tomando A como o valor do coeficiente repetido na última coluna (maior $\theta$ ), temos:

$$
a_{\text {analitico }}=\frac{K \alpha_{1}}{2 \sqrt{A}}=\frac{1,78901}{2 \sqrt{0,0612}}=3,6158 \AA
$$


Os valores dos denominadores das frações $\operatorname{sen}^{2} \theta$ nas colunas indicam a família de planos onde ocorre difração. Os valores coincidem com os de $h^{2}+k^{2}+l^{2}$ acusados na análise pelo método teórico.

Tabela 1. Método Analítico.

\begin{tabular}{|c|c|c|c|c|c|c|c|}
\hline Pico & $2 \theta(\underline{\mathrm{O}})$ & $\operatorname{sen}^{2}(\theta)$ & $\frac{\operatorname{sen}^{2}(\theta)}{3}$ & $\frac{\operatorname{sen}^{2}(\theta)}{4}$ & $\frac{\operatorname{sen}^{2}(\theta)}{8}$ & $\frac{\operatorname{sen}^{2}(\theta)}{11}$ & $\frac{\operatorname{sen}^{2}(\theta)}{12}$ \\
\hline 1 & 50,6707 & 0,1831 & $\mathbf{0 , 0 6 1 0}$ & 0,0458 & 0,0229 & 0,0166 & 0,0153 \\
\hline 3 & 59,2397 & 0,2442 & 0,0814 & $\mathbf{0 , 0 6 1 1}$ & 0,0305 & 0,0222 & 0,0204 \\
\hline 5 & 88,7766 & 0,4893 & 0,1631 & 0,1223 & $\mathbf{0 , 0 6 1 2}$ & 0,0445 & 0,0408 \\
\hline 7 & 110,2442 & 0,6730 & 0,2243 & 0,1683 & 0,0841 & $\mathbf{0 , 0 6 1 2}$ & 0,0561 \\
\hline 9 & 117,9547 & 0,7343 & 0,2448 & 0,1836 & 0,0918 & 0,0668 & $\mathbf{0 , 0 6 1 2}$ \\
\hline
\end{tabular}

A partir dos picos de $K \alpha_{1}$ e $K \alpha_{2}$, podem ser calcular todos os valores teóricos do parâmetro de rede do cobre pelo método teórico. Relacionando-os com os respectivos valores da função erro de Nelson-Riley, obtém-se a dispersão exposta na figura 3.

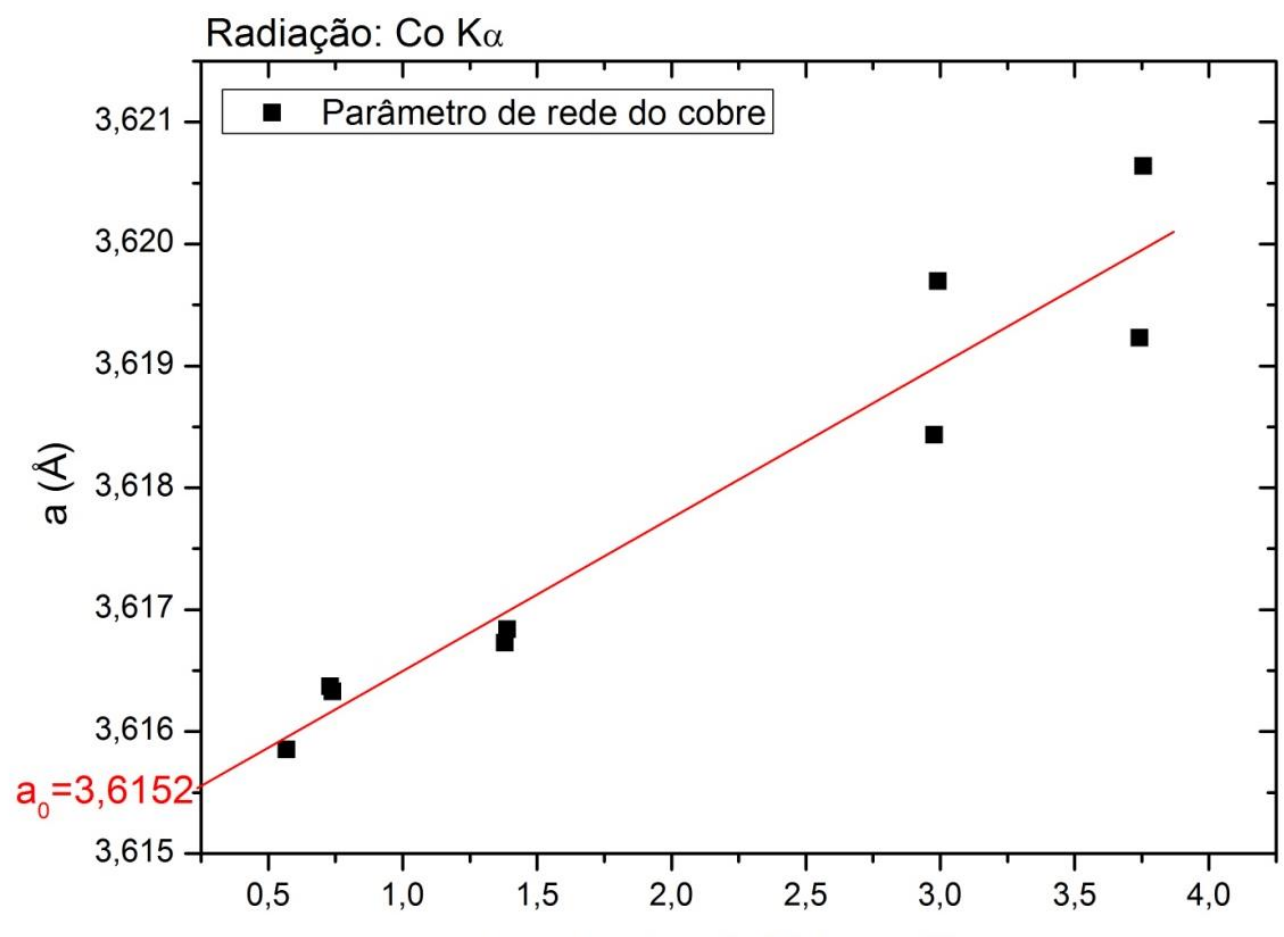

Função Erro de Nelson-Riley

Figura 3. Dispersão de dados para o Método de Nelson-Riley.

Através de uma regressão linear, podemos identificar o valor aproximado de parâmetro de rede quando a função erro é zero, em $2 \theta=180^{\circ}$. Por meio deste cálculo, encontramos $a_{\text {Nelson-Riley }}=3,6152 \AA$.

Por fim, utilizando os valores obtidos pelo Método Teórico também, podemos calcular os coeficientes prescritos pelo método de Cohen para o cálculo do parâmetro de rede com precisão.

$$
a_{\text {Cohen }}=3,6143 \AA
$$


O banco de dados PDF-2 da Panalytical, ficha 00-004-0836, acusa um valor de 3,6150 ̊ para o parâmetro de rede do cobre. Os valores calculados obtiveram, portanto, uma proximidade mínima de $99,98 \%$ do valor indicado na referência.

\subsection{Orientação preferencial}

Por meio dos difratogramas obtidos experimentalmente pode ser analisada, qualitativamente, a orientação preferencial, tanto na depreciação quanto na intensificação de picos. As figuras 4 e 5 mostram comparações entre picos das amostras sem deformação e com $85 \%$ de deformação por laminação.

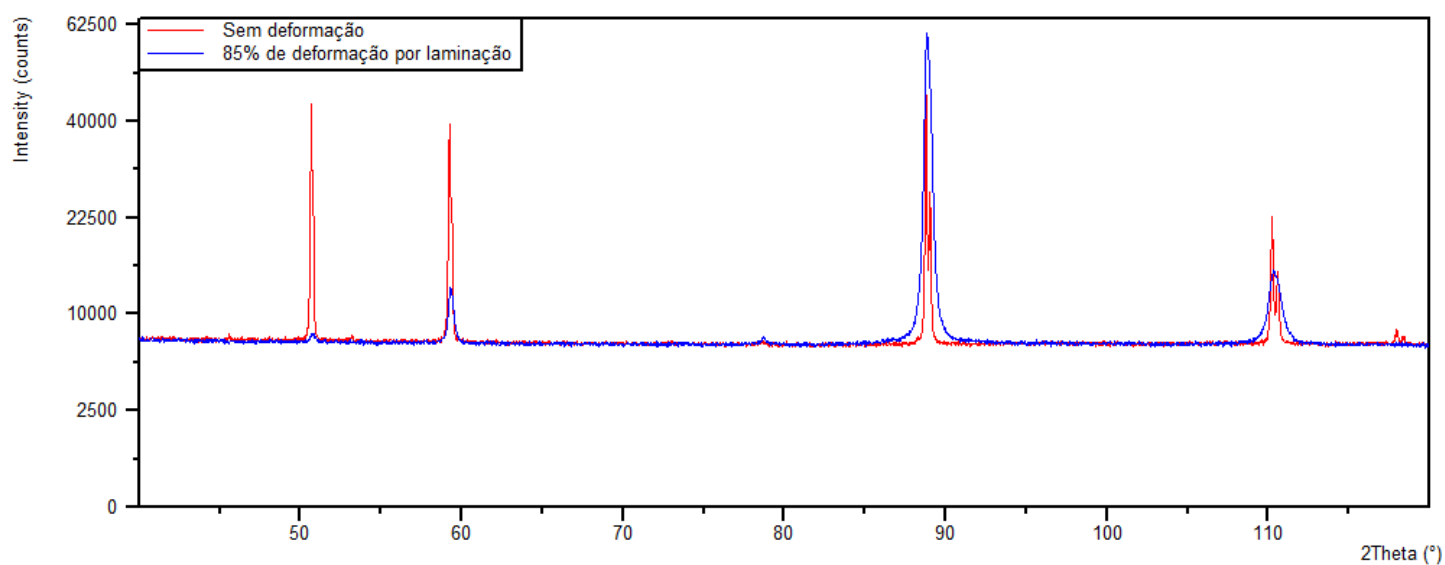

Figura 4. Comparação entre os difratogramas das amostras sem deformação por laminação e com $85 \%$ de deformação por laminação.

Outra comparação realizada entre as amostras pode ser visualizada na figura 5. Nesta, a razão entre a intensidade integrada dos picos e a intensidade integrada da amostra sem deformação por laminação são mostradas para cada amosta.

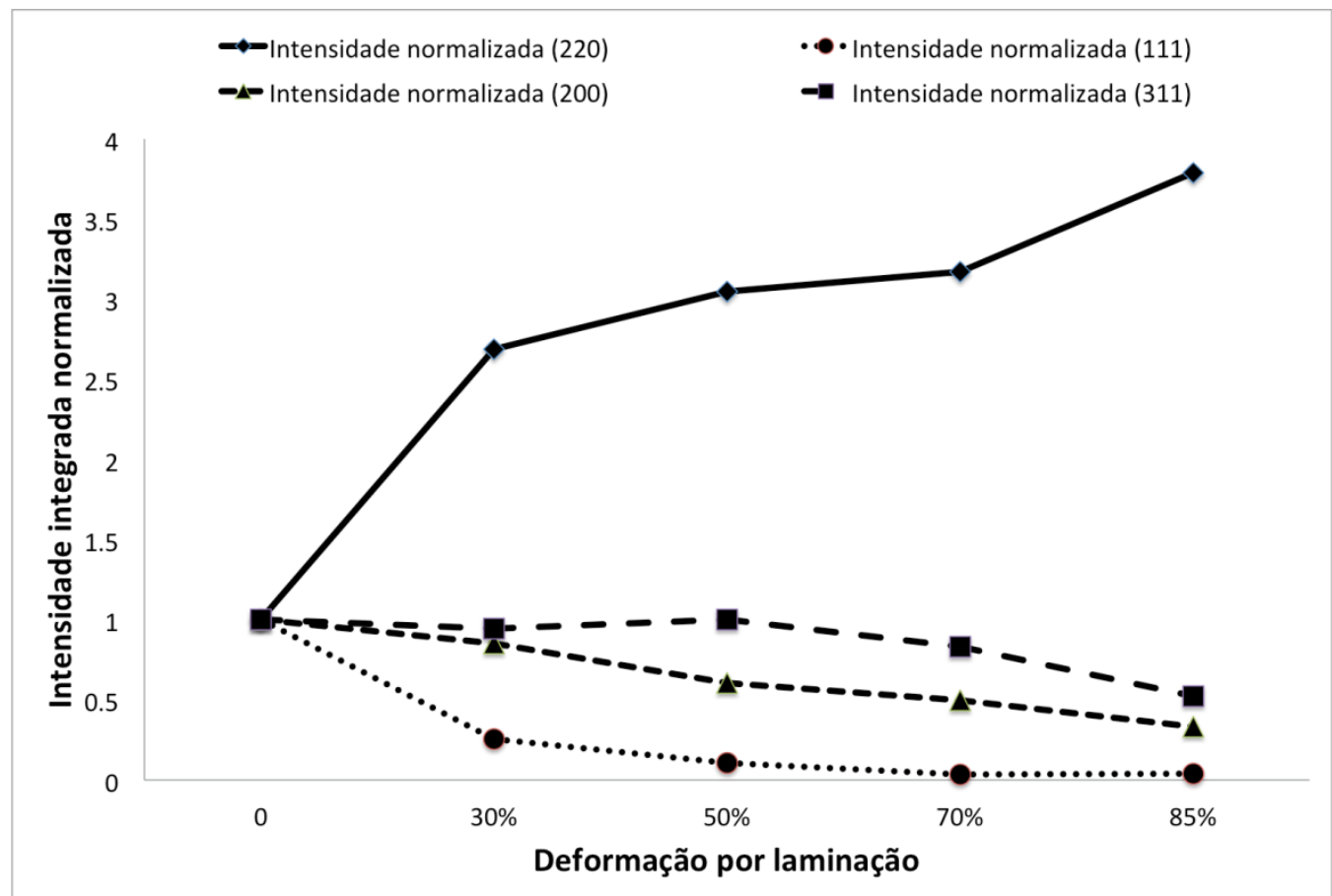

Figura 5. Variação da intensidade integrada para os picos de difração analisados com o processamento por laminação. 
Obtiveram-se também os coeficientes $C$ expostos na tabela 2. Pode-se observar a tendência de crescimento do coeficiente para o plano (220) e de decréscimo dos outros planos, identificando quantitativamente a orientação preferencial inserida a partir dos processos de laminação.

Tabela 2. Medições dos coeficientes $C$ para cada amostra.

\begin{tabular}{|c|c|c|c|c|}
\hline & \multicolumn{4}{|c|}{$C_{i}$} \\
\hline Def. por Laminação & $(111)$ & $(200)$ & $(220)$ & $(311)$ \\
\hline CR & 0,120 & 1,639 & 0,792 & 1,449 \\
\hline $30 \%$ & 0,032 & 0,258 & 2,259 & 1,450 \\
\hline $50 \%$ & 0,012 & 0,170 & 2,384 & 1,433 \\
\hline $70 \%$ & 0,004 & 0,146 & 2,604 & 1,246 \\
\hline $85 \%$ & 0,005 & 0,097 & 3,111 & 0,786 \\
\hline
\end{tabular}

Outra forma de visualizar quantitativamente a evolução da textura é por meio do parâmetro $\sigma$. Por meio da figura 6 , pode ser verificado o aumento do valor do parâmetro com os processos de laminação. Este resultado está condizente com o desvio mais intenso dos valores de coeficiente $\mathrm{C}$ para os planos em cada amostra. O que se expõe por meio d parâmetro é uma média desses desvios.

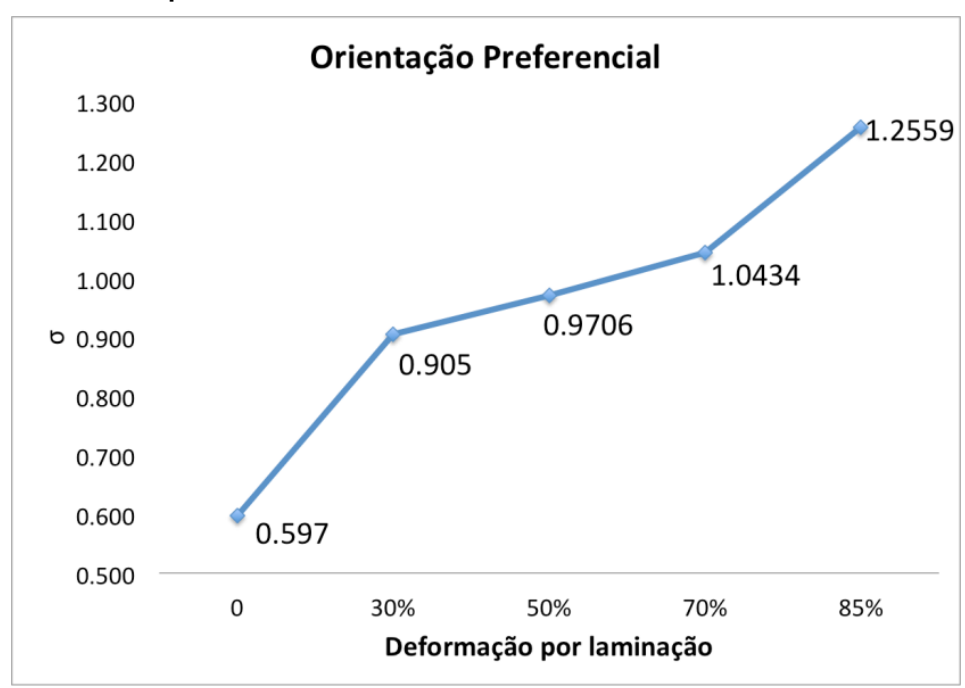

Figura 6. Comparação entre os parâmetros $\sigma$ das amostras.

A partir dos dados de análise de orientação preferencial, pode ser verificada a tendência das amostras de apresentarem textura cada vez mais acentuada de acordo com o aumento de deformação por laminação. Tal fato é esperado, pois deformações plásticas mais intensas levam a rotações mais acentuadas dos grãos cristalográficos, que se alinham de acordo com a direção de laminação. Os grãos foram rotacionados de maneira a se orientarem com o plano (220), gerando o incremento de intensidade para este plano e do decréscimo de intensidade para os outros. 


\subsection{Tamanho de cristalito}

Por meio dos dados expostos, podemos plotar os gráficos de $B_{r} \cos \theta$ em função de $\operatorname{sen} \theta$. Os gráficos estão representados na figura 7 .
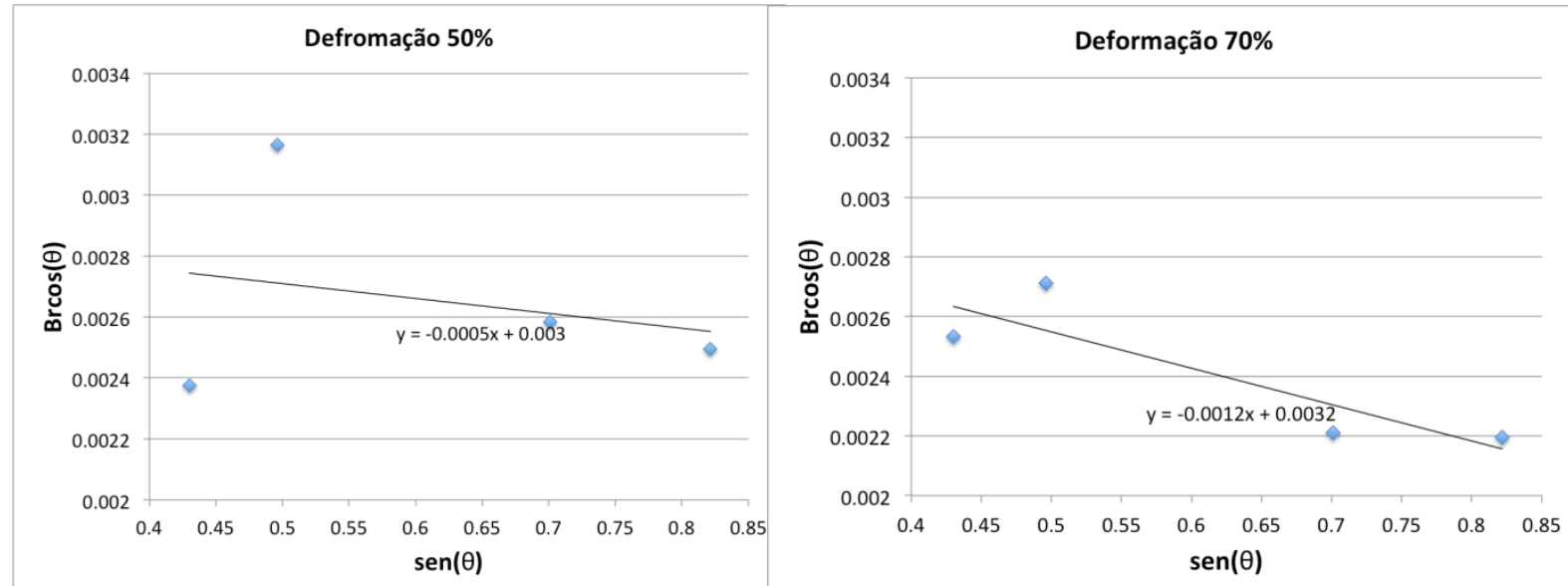

Figura 7. Gráficos $B_{r} \cos \theta$ em função de $\operatorname{sen} \theta$. À esquerda, tem-se o gráfico da amostra com $50 \%$ de deformação e, à direita, tem-se o da com $70 \%$.

Por meio da regressão linear realizada, podem ser extraídas as informações sobre tamanho de cristalito e deformação residual expostas na tabela 3.

Tabela 3. Resultado para análise de tamanho de cristalito.

\begin{tabular}{|c|c|c|c|}
\hline Amostra & $\frac{0,9 \lambda}{L}$ & $\mathrm{~L}(\AA)$ & $\eta$ \\
\hline $50 \%$ deformação & 0,003 & 537,092 & $-0,0005$ \\
\hline $70 \%$ deformação & 0,0032 & 503,524 & $-0,0012$ \\
\hline
\end{tabular}

Por meio dos resultados expostos, observa-se que mesmo após recozimento, ainda pode ser observada deformação residual significativa na rede cristalina do cobre conformado por laminação. Verificamos que a deformação presente na rede é negativa, ou seja, possui caráter compressivo. Tal fato condiz com o processo de laminação, onde a amostra metálica é comprimida plasticamente pelos rolos laminadores.

Também, a amostra que sofreu deformação plástica mais intensa apresentou o menor tamanho de cristalito. Isto se deve ao fato de haver mais centros de nucleação por causa da deformação plástica. Portanto, haverá mais grãos presentes e, consequentemente, esses serão menores.

Vale observar que a não coincidência dos pontos do gráfico de $B_{r} \cos \theta$ em função de $\operatorname{sen} \theta \operatorname{com}$ a regressão linear realizada indica que a amostra possui diferentes tamanhos de cristalito ao longo de sua área.

Por fim, é necessário enfatizar que a análise do tamanho de cristalito por meio da largura a meia altura não é tão precisa. Picos de difração que ocorrem em ângulos $2 \theta$ superiores tendem a apresentar o pico $K \alpha_{1}$ e $K \alpha_{2}$ bem definidos. Isto leva a dificuldades no momento de determinar a largura a meia altura do pico como um todo. 


\subsection{Análise quantitativa}

Analisando os dados do difratograma, verificou-se que as fases componentes são ferro e cobre, referenciados pelas ficha PDF-2 03-065-4899 e 01-089-2838, respectivamente. A comparação dos padrões de difração está exposta na figura 8.

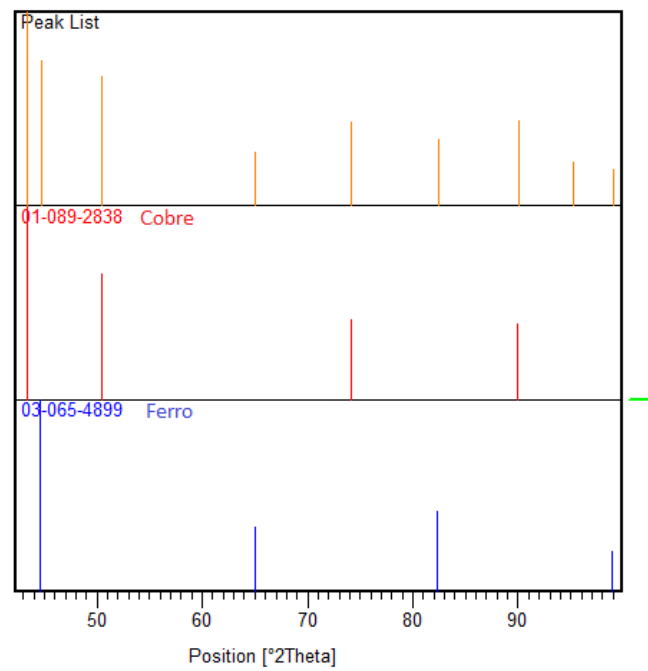

Figura 8. Comparação dos padrões de linha das fichas e do difratograma experimental.

Tendo o conhecimento das fases presentes, pôde ser inserido no software de análise fichas cristalográficas do ferro e do cobre, extraídas do Crystallography Open Database (COD). As fichas utilizadas foram a 4105681 para o cobre e a 4113928 para o ferro. Então, teve início o processo de refinamento para a análise quantitativa.

A partir do refinamento de Rietveld realizado, obtiveram-se os resultados para GOF e composição de fases exibidos na tabela 4.

Tabela 4. Resultados para análise de Rietveld.

\begin{tabular}{|c|c|c|c|}
\hline Método & GOF & \%p Ferro & \%p Cobre \\
\hline Automático & 1,87212 & 38,3 & 61,7 \\
\hline Semi-automático & 1,67760 & 43,6 & 56,4 \\
\hline Manual & 1,66056 & 40,8 & 59,2 \\
\hline
\end{tabular}

Como esperado, o método manual apresentou melhor aproximação ao difratograma experimental em comparação aos métodos semi-automático e automático, obtendo GOF de 1,66056.

\section{CONCLUSÃO}

Pode-se verificar sua eficiência na identificação do material de determinada amostra. A prática mostrou que o tratamento adequado da amostra, a devida aplicação dos ajustes de inclinação, a utilização correta do goniômetro e de seu software e a busca por fichas que correspondem aos picos fornecidos pela difração nos levam a obter um resultado compatível com a realidade, demonstrando, assim, a confiabilidade da técnica. 
A partir da manipulação dos métodos apresentados para cálculo do parâmetro de rede, pode-se averiguar a validade dos métodos, tendo em vista à semelhança dos resultados alcançados com o valor do parâmetro de rede encontrado nas fichas de referência da Panalytical. Dentre eles, o valor que mais se aproximou do apresentado na ficha foi o calculado a partir do Método de Extrapolação, diferindo vagamente do segundo método de precisão, que é o Método de Cohen. Todos os valores, porém, apresentaram divergências menores que $0,02 \%$, dentro do aceitável.

Através dos resultados apresentados para orientação preferencial, pode-se verificar a influência dos processos de conformação mecânica na estrutura cristalográfica dos materiais. As altas taxas de deformação impostas à amostras durante a laminação resultaram em orientação preferencial cada vez mais pronunciada, o que influencia sobremaneira o desempenho mecânico do material.

Por meio da análise de cristalito, observou-se a presença de deformação residual mesmo após tratamento térmico de recozimento. A dispersão dos pontos do gráfico de $\boldsymbol{B}_{r} \cos \boldsymbol{\theta}$ em função de $\operatorname{sen} \boldsymbol{\theta}$ demonstra ainda a heterogeneidade do tamanho de cristalito na amostra e, por conseguinte, do material em si.

A partir das análises de refinamento de Rietveld, verifica-se que o tratamento matemático de dados experimentais, particularmente para o caso da difração de raios $\mathrm{X}$, constitui uma maneira prática e precisa de se obter resultados quantitativos, neste caso, porcentagem de fases. A utilização de técnicas automáticas de análise permite ainda uma rápida avaliação experimental, viabilizando sua aplicação em setores onde tempo é uma variável fundamental. $\mathrm{O}$ método manual apresentou 0 melhor desempenho na aproximação do difratograma. A aproximação da modelagem de Rietveld ao conjunto de dados experimentais foi estatisticamente satisfatória para os três tipos de refinamento realizados.

\section{REFERÊNCIAS}

1 CULLITY, B.D.; STOCK, S. R. Elements of x-ray diffraction; $3^{a}$ ed., Nova Jersey: Prentice Hall, 2001.

2 SURYANARAYANA, C.; NORTON, M.G.; em X-Ray Diffraction: A Pratical Approach; 1a ed., Nova lorque: Springer, 1998.

3 PADILHA, A. F.; SICILIANO Jr., F. Encruamento, recristalização, crescimento de grão e textura. São Paulo: ABM, 3a edição. 2005. 232p.

4 DIETER, G. E. Mechanical Metallurgy. SI Metric ed. Londres: McGraw-Hill Book Company, 1988.128p.

5 VANDER VOORT, G. F. Metallography: principles and practice. $2^{\circ}$ ed.. New York: McGraw-Hill, 1984.. 